\title{
P-0672 Evaluation of early vascular damage by Cardio-Ankle Vascular Index in patients with T2DM and chronic kidney disease
}

\section{Carlone A. ${ }^{1}$, Leto ${ }^{1}{ }^{1}$, D’Onofrio L. ${ }^{1}$, Lanzillo N. ${ }^{1}$,Mignogna C. ${ }^{1}$, Zampetti S. ${ }^{1}$, Tartaglione L. ${ }^{2}$, Muci M.L. ${ }^{2}$, Rotondi S. ${ }^{2}$, Buzzetti R. ${ }^{1}$, Mazzaferro S. ${ }^{2}$}

${ }^{1}$ Department of Experimental Medicine, "Sapienza" University of Rome, Italy

${ }^{2}$ Department of Cardiovascular, Respiratory, Nephrologic, Anesthesiologic and Geriatric Sciences "Sapienza" University of Rome, Italy

Background and aims: Type 2 diabetes mellitus (T2DM) is the major cause of end stage renal disease in the world. Cardiovascular disease (CVD) almost invariably affects diabetic patients and chronic kidney disease (CKD) is an additional risk factor for CVD. Vascular stiffness, evaluated as arterial Pulse Wave Velocity (aPWV), is known to correlate with fasting glucose, HbA1c and diabetes duration. CAVI is a new technique to measure vascular stiffness from ascending aorta to ankle that simultaneously assess PWV and Ankle Brachial Index (ABI). We aimed to evaluate with CAVI method, the vascular stiffness of T2DM patients with GFR $>60 \mathrm{ml} / \mathrm{min} / 1.73 \mathrm{~m}^{2}$. We searched for possible relationships of this index with the duration of T2DM, metabolic parameters (fasting glucose, HbA1c) and microalbuminuria (MAB, threshold value $30 \mu \mathrm{m} / \mathrm{L}$ ).

Materials and methods: we enrolled 80 T2DM patients (age $=$ $54.5 \pm 4.1$ years, duration disease $=3.6$ years $\pm 1.5, \mathrm{HbA} 1 \mathrm{c}=$ $6.5 \pm 0.9 \%, \mathrm{GFR}=94.3 \mathrm{ml} / \mathrm{min} / 1.73 \mathrm{~m}^{2} \pm 9.9, \mathrm{MAB}=28.2$ $\mu \mathrm{m} / \mathrm{L} \pm 86.6)$ without clinical evidence of atherosclerotic disease, and 40 healthy controls from April to October 2016. Inclusion criteria were: age $\leq 60$ years; T2DM $<10$ years; CKD stage 1 (GFR $\geq 90 \mathrm{~mL} / \mathrm{min} / 1.73 \mathrm{~m}^{2}$ ) and 2 (GFR $>60<90 \mathrm{ml} / \mathrm{min}$ $/ 1.73 \mathrm{~m}^{2}$ ). Exclusion criteria were: micro or macrovascular complications, autoimmune diabetes or diseases, previous insulin therapy, history cancer or kidney transplantation. They underwent blood and urine tests, carotid ecodoppler, and vascular stiffness measurement (CAVI by VaSera1500, Fukuda Denshi Co.) Statistical analysis was performed with Student $t$ test and ANOVA test.
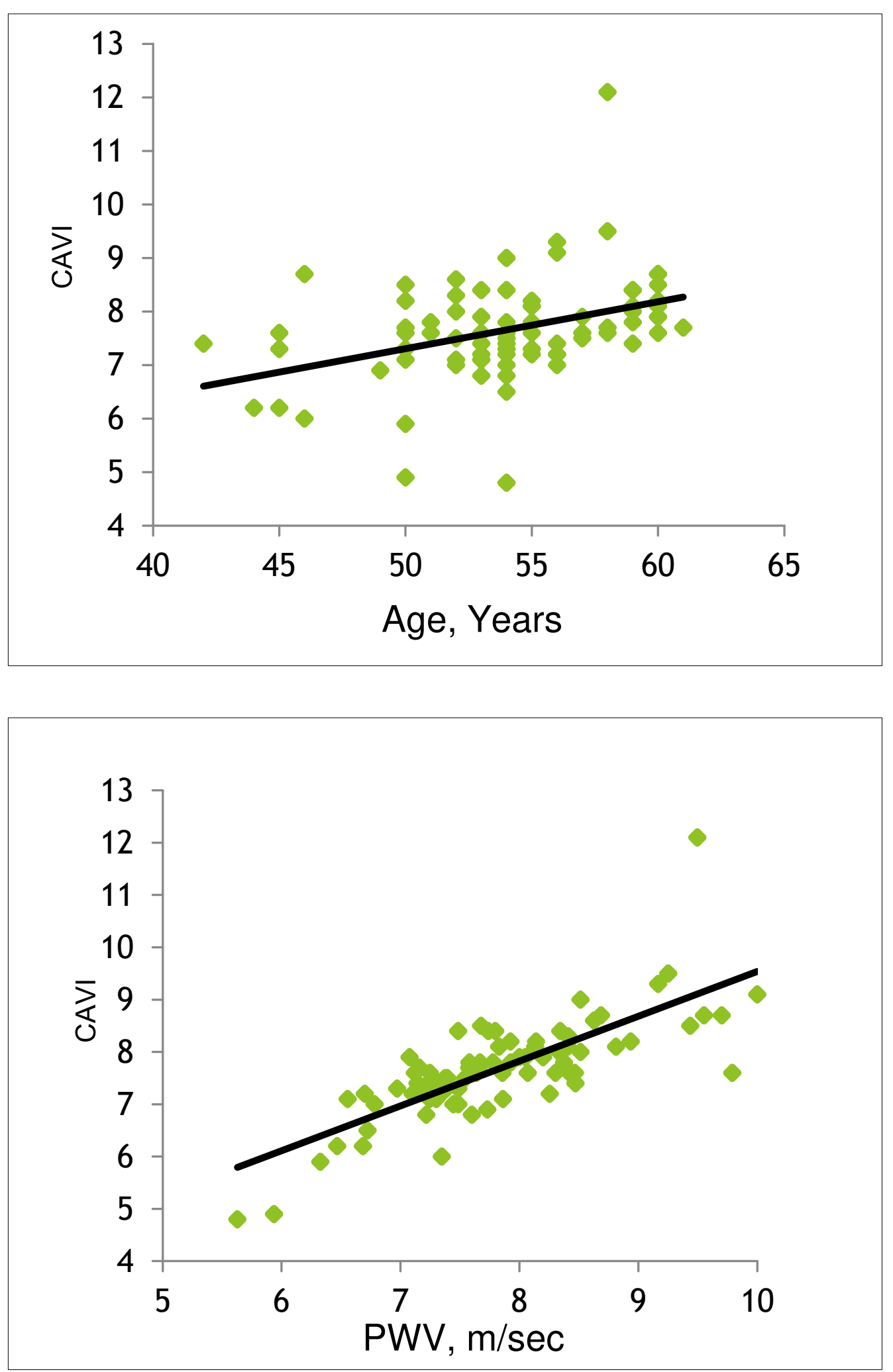

Results: CAVI values did not differ between T2DM and healthy subjects (CAVI $=7.66 \pm 0.97 v s 7.48 \pm 0.76 ; p: n s)$ and were positively correlated to age $(r=0.39 ; p<0.05)$ and $\mathrm{PWV}(r=0.77$; $p<0.05)$ but not to BP, duration of diabetes, Hb1Ac and GFR. Compared to those without MAB, patients with MAB (>30 $\mu \mathrm{m} / \mathrm{L})$ showed higher values of CAVI (8.57 \pm 1.55 vs $7.58 \pm 0.91)$ $p=0.008$ and PWV (8.41 \pm 0.80 vs $7.74 \pm 0.85) p=0.03$. T2DM patients were subsequently divided in three groups for different levels of $\operatorname{MAB}(<10,10-30,>30)$. There was a significant difference of CAVI between the study population divided according to the level of MAB (7.52 \pm 0.82 vs $7.68 \pm 1.05$ vs 8.57 \pm 1.55 ) p: 0.027 analyzed with ANOVA test .

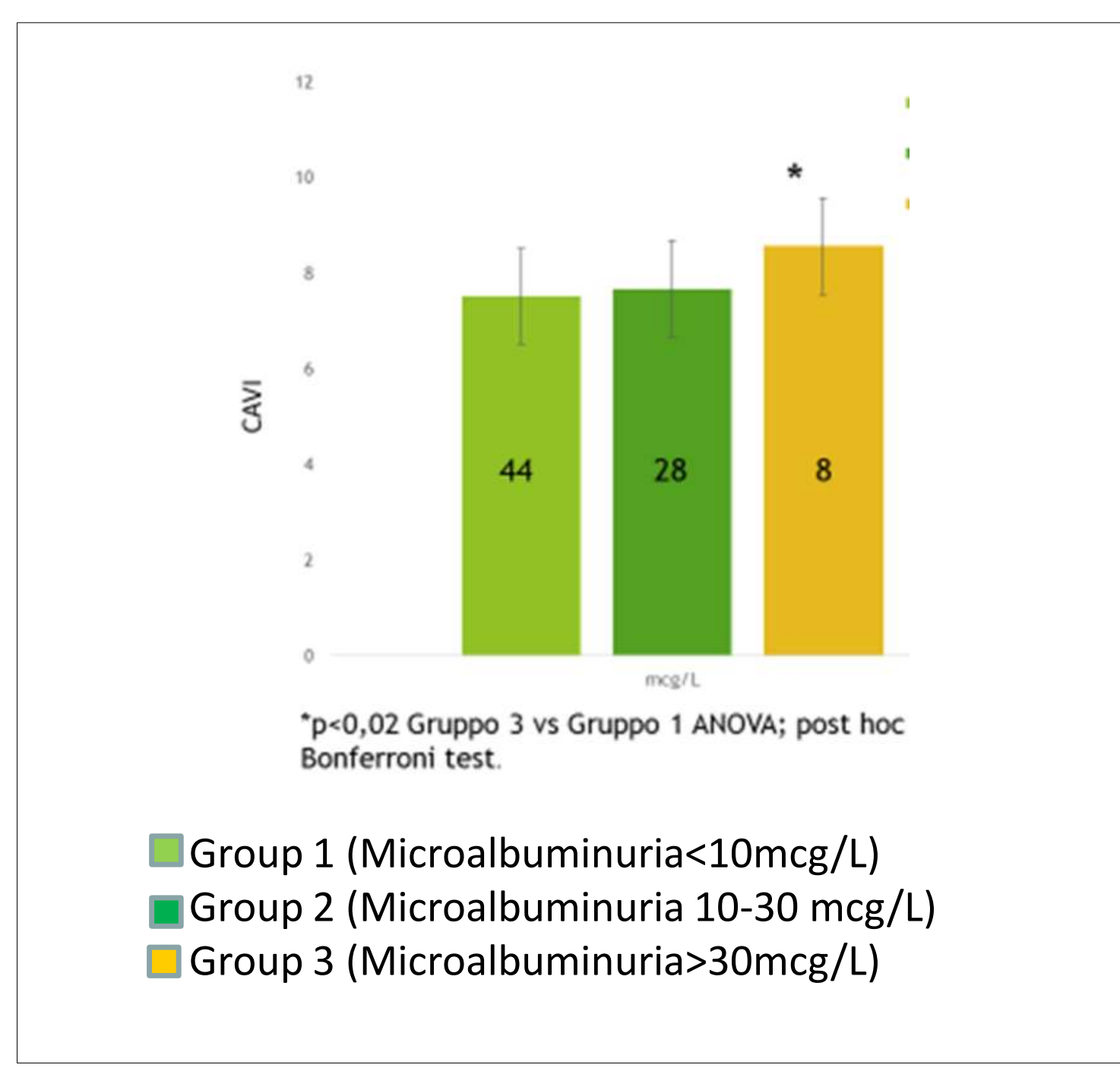

\begin{tabular}{|c|c|c|c|c|}
\hline & $M A B<10$ & MAB $10-30$ & $M A B>30$ & ANOVA \\
\hline Age (years) & $53.84 \pm 4.40$ & $54.04 \pm 4.39$ & $54.87 \pm 3$ & N.S. \\
\hline CAVI & $7.52 \pm 0.82$ & $7.68 \pm 1.05$ & $8.57 \pm 1.55$ & $p: 0,027$ \\
\hline PWV & $7.66 \pm 0.77$ & $7.85 \pm 0.96$ & $8.41 \pm 0.80$ & N.S. \\
\hline $\begin{array}{l}\text { GFR } \\
\left(\mathrm{ml} / \mathrm{min} / 1,73 \mathrm{~m}^{2}\right)\end{array}$ & $94.10 \pm 10.3$ & $93.73 \pm 9.97$ & $97.6 \pm 6.87$ & N.S. \\
\hline
\end{tabular}

Conclusions: CAVI is positively correlated to PWV in T2DM patients, but not to BP and could therefore be considered a useful screening test for vascular damage which is unaffected by BP shifts. In particular, CAVI could help detect vascular damage in diabetic patients with $M A B>30 \mu \mathrm{m} / L$ and GFR $>60 \mathrm{ml} / \mathrm{min} / 1.73 \mathrm{~m}^{2}$.

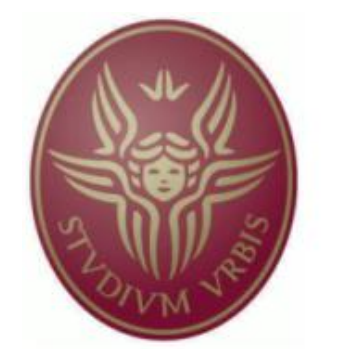
SAPIENZA UNIVERSITÀ DI ROMA 